\title{
Less but Better? Teaching Maths in Further Education and Collateral Growth
}

\author{
Lawrence Nixon ${ }^{1, *}$ and John B. Cooper ${ }^{2, *}$ \\ 1 Faculty of Education and Society, University of Sunderland, Sunderland SR1 3SD, UK \\ 2 Progression Studies, East Sussex College Group, Eastbourne BN21 2UF, UK \\ * Correspondence: lawrence.nixon@sunderland.ac.uk (L.N.); john.cooper@sussexdowns.ac.uk (J.B.C.); \\ Tel.: +44-919-515-2351 (L.N.); +44-30300-39013 (J.B.C.)
}

Received: 4 February 2020; Accepted: 3 March 2020; Published: 6 March 2020

\begin{abstract}
The paper presents and explores the experience of maths students studying in a context shaped by a core concept maths curriculum. The three vignettes that illuminate experience are drawn from a larger research project that worked with five teachers and 630 learners aged 16-18 in Further Education classrooms in England. Analysis involved distinguishing different understandings of being good at maths, different views of a good maths curriculum and identifying enablers and barriers to being a 'successful' maths student. Dewey's ideas about focused experience and collateral learning were used to deepen this analysis. The paper reports a surprising finding. In some cases, students recognize the positive impact learning maths had on developing their wider human capabilities. Maths teachers in England, working in the context of 'new public management', may find reasons to take heart from the accounts of teaching and learning presented. For the international reader who is grappling with the challenge of reengaging maths students, the accounts of what matters to students could spur a reconsideration of priorities and practice.
\end{abstract}

Keywords: maths teaching; curriculum; student experience; wellbeing; further education

\section{Introduction}

The paper reports on an unexpected consequence of introducing a core concept maths curriculum. It was found that the introduction of a maths curriculum focused on eight core topics: transformations, area, probability, angles, percentages, ratio, algebra and linear graphs, had the unintended consequence of making more space for the experience of maths learning to appear and be considered. This paper reports on our attempts to understand what matters to students.

The article describes the context of maths teaching in terms of the teachers' work to implement a new a core concept maths curriculum. It presents three vignettes of student experience drawn from a larger research project that works with five teachers and 630 learners aged 16-18 in Further Education classrooms. Analysing student experiences of maths learning involved distinguishing different understandings of being good at maths, different views of what a good maths curriculum should be like and identifying the enablers and barriers to being a 'successful' maths student. The paper argues that trying to understand the experience of maths students is an important part of maths teachers' work. It is a part of the job that is all too easily displaced by the search for more effective teaching strategies.

The first part of the article describes the particular context of maths teaching shaped by four common policy drivers shaping teaching and learning across Further Education (FE) and the implementation of a core content curriculum. The second part of the paper presents three vignettes that bring to life the experience of maths students in this context, what they valued, what worried them and how their views of themselves and maths changed over time. The surprising finding reported is 
that students recognized the positive impact that learning maths had on developing their wider human capabilities. The final part of the paper presents our findings and recommendations in terms of three qualified questions that ask maths teachers to consider what they might change in their classrooms to improve the experience of students.

\section{Materials and Methods}

\subsection{Materials}

The case explored in this paper is maths teaching and learning in number of maths classrooms in a large Further Education college in the south of England. Before going on to describe this particular teaching situation, setting the scene requires us to recall four factors that will be familiar to classroom teachers across the sector and beyond. Reminding ourselves of these common factors builds bridges between the particularity of this case and other maths classrooms.

Firstly, all teachers in England work in what Stephen Ball calls a culture of new public management. This culture values success rates and efficiency. It prizes target setting, monitoring and achievement ranking [1]. The use of automated student progress monitoring systems requires maths teachers to keep a record of learner progress. Such 'traffic lighted' progress records are reviewed in regular meetings between maths teachers and managers [2]. The performance of maths teachers is further judged against overall success and achievement rates. In the classroom, this culture is expressed in demands to demonstrate learner performance against 'stretch and challenge' targets [3,4]. It is also felt in the demand that lessons are well paced. The original OFSTED observation that 'attainment is strongly affected by the quantity and pacing of instruction' [5] had been interpreted in some organisations to mean that a good lesson explicitly demonstrates progress in every $20 \mathrm{~min}$ section. This culture can be summed up in the mantra 'teach more, teach faster'. Student progress, is likewise, reduced to an assessment of written responses against initial predicted grades. In these ways, an efficient, value-for-money education is evidenced.

Secondly, in England, major reforms to GCSE specifications and exams were introduced in 2015 and the first exams were sat in 2017. Some topics were dropped from the maths foundation tier exam and replaced with harder questions from the higher tier exam. The new exam consisted of three papers, instead of two. Calculators were allowed in two out of the three exams, mental arithmetic lost some value as a result and large swathes of skills, taught over 11 years of school, had their exam value diminished. The range of topics to cover number 127 at the foundation level. The introduction of these new specifications gave maths teachers and students the challenge of how to cover this huge range of topics in a way that led to success.

Third, FE teachers typically meet students who have not thrived in their previous maths classrooms. The Joint Qualification Council report around a 60\% pass rate for GCSE maths in the years 2017 to 2019. A total of 200,000 students under 19 re-sitting English and maths GCSEs in FE classrooms in the UK are typically made up of the $40 \%$ who do not pass the exam in secondary school [6]. This experience of past failure means that teachers often meet students who are discouraged, disengaged and uninterested. It is a big part of the FE maths teachers' work to face up to and turn around these negative attitudes toward maths. This paper explores the possibilities of improving those attitudes.

Finally, the introduction of the study programme funding regime in 2014 linked student success in English and maths closely to income generation [7]. Combined with pressures from central government to define success more narrowly in terms of the new, more challenging GCSE qualification, there has been a sector-wide shift in the maths programmes studied. At present, for every three students studying for a GCSE qualification, there is now only one student studying for the less ambitious Functional Skills qualification. The financial necessity for colleges to respond to these policy drivers may go some way to explain the current dismal maths achievement rates in FE. Some research puts the percentage of FE students passing the new GCSE as low as 5\% [8] (p. 3). 
This research study investigates the particular practice of maths teachers and students in a large college in the south of England. The uniqueness of this maths practice can be gleaned by describing the college setting and the novel maths curriculum developed to deliver GCSE re-sit maths. The college has around 700 students across two campuses re-sitting maths and around 160 taking Level 1 Functional Skills exams. The five GCSE teachers are predominantly ex-secondary school teachers with a shared commitment to offer some success to students who have not managed to achieve their full potential in secondary education. Students are offered three hours of maths per week over 33 weeks. Class sizes average around 22 and the maths and English departments work in a close relationship. The majority of students are on vocational courses, with some doing A levels.

In the challenging broader context set out above, in 2016, the maths team began to explore how they could improve student engagement and achievement within maths. In a series of discussions with an external, critical friend, they were confronted first by the observation that "your teaching is great. You just need better learners". They decided this statement was challenging them to find a way to give students the experience of maths success. Second, in discussions about how this could be achieved, the critical friend suggested concentrating on a limited number of topics. The hope was that concentrating on eight topics, repeated over an extended period, would give the students a better chance of mastering the topics and tasting success.

These discussions spurred the maths team to develop a core concept maths curriculum, branded as the 'Essential 8 programme'. In order to identify the eight core maths topics, the team trawled through past papers, calculating marks and frequency and eventually settling on the eight topics. The team then developed a curriculum that allowed students to be introduced to each topic, revisit the topic to consolidate learning and then review its relationship with other topics. The hope was that this form of sequencing would allow students to build their confidence by getting the answers right. The team was encouraged in this approach by Jo Boaler's advice: 'tell students you don't value fast work. Mathematical thinking is about depth not speed... [and to] value depth, creativity, different ways of thinking about math, and different explanations' [9] (p. 275).

The programme developed revolved around two printed workbooks [10,11]. Each booklet focuses on eight maths topics: transformations, area, probability, angles, percentages, ratio, algebra and linear graphs. These topics were presented as a repeating series of questions. A corresponding set of classroom posters were also developed. Some other UK colleges are now also using the programme.

In any one academic year, the same eight topics are taught three times. There are entry and exit online assessments, along with three end-of-term assessments, which produce a personal learning checklist used for independent study. This repetition of a learning sequence gives learners a chance to develop their understanding and confidence with these topics. As Nuthall suggests, presenting a topic three times makes the topic stick [12].

In developing a limited core maths concept curriculum [13] the team hoped to develop a concrete way to respond to the external demands that did not fall into the trap of addressing a more demanding maths specification with faster, quicker teaching. They hoped that, by slowing down the pace and limiting the range of topics covered, they would give learners a chance to gain a sense of what they were doing, where they were going and a sense that they could return to topics not yet fully mastered. They hoped that this stable environment would promote a common maths language that learners actually understood. The aim was to give students "a genuine situation of experience-that there be a continuous activity in which he is interested for its own sake" [14] (p. 192). It could also contribute to building a community of learners and give everyone in the class a chance to succeed. It was in this particular context that it became easier to hear what students had to say about themselves and learning maths.

\subsection{Methods}

This paper comes out of a larger research study. The larger study uses a mixed methods approach [15] to draw on qualitative and quantitative data to explore the opportunities of teaching 
maths using a core concept curriculum. The research cohort consisted of 429 male and female learners, all aged between 16 and 19. The vast majority have been through secondary education in the UK, with around $5 \%$ having been home-schooled or taught in other countries. The larger study used a range of data collection tools including mass surveys, written feedback, verbal questioning, focus groups, interviews and field notes. Quantitative and qualitative data were triangulated in order to cross check reports of experience with harder outcomes data.

This paper only reports on a qualitative aspect of the larger study. It aims to better understand the experience of maths students. Henrik von Wright makes an important distinction between different meanings of the term understanding. Causal and teleological explanations further our understanding of things in a technical way. For example, a behaviorist account of 'improving' teaching claims to identify stimuli effective in causing the desired response. The enticing look of such understandings push from view the importance of understanding human experience. In this sense the term draws attention to all those situations and conversations where other people's experiences, their intentions and their motives are all important [16] (p. 6). The vignettes presented offer an empathetic understanding of the student's experience of maths. As such, they offer what Wittgenstein calls 'objects of comparison' [17] (p. 130). These objects, in their similarity and difference from the reader's experience of teaching, do not seek to make claims about 'impact' but rather provoke conversations about what really matters in the classroom.

Following Robert Stake, we adopted a naturalist case study approach to investigating and understanding student experience [18]. Field notes were kept for the purpose of recording learner experiences as and when they became apparent. Out of 19 journal entries, six stood out as being particularly rich in meaning and worthy of deeper analysis. From these six, three were finally selected for inclusion in this paper. These three moments of student expression were not representations of the overall collection of vignettes. Rather, they were selected for their individual significance. The richness of these moments made them worthy of careful and detailed analysis. As Robert Stake puts it 'the real business of case study is particularization, not generalization' [18] (p. 5).

Making sense of the moments of student expression was an evolutionary process. It began with our 'etic' issues and questions. That is, our initial views as researchers and teachers about what mattered. As the we looked and relooked at what the students had to say, 'emic' accounts of what mattered emerged. Insights and issues from the inside, from the perspective of students, came into view and shaped the report. This was a tentative, iterative process of progressive focusing [18] (p. 9) and [19-23].

Following Stake, we used issue questions to focus on problems and concerns [18] (pp. 15-34). These issue questions emerged as we went back and forth working to make sense of the struggles of students seeking to become themselves through their work with others. The development of these questions directed us to those moments of conflictual outpouring and/or spontaneous speaking out that brought background human concerns into the classroom. These moments, when considered, carefully illuminated operative assumptions, claims to authority and different views about what really mattered.

The issue questions that emerged as we worked to get closer to the emic situation were:

Are there incompatible definitions of being good at maths in play at the college?

Who says what counts as a good maths curriculum at the college?

Are the goals of a maths curriculum based on a small set of core concepts realistic?

Connelly and Clandinin argue for the potential of presenting these moments of conflictual outpouring as vignettes, moments of contextualized conversation [23]. Seeking answers to the three issue questions guided the discussion of the vignettes. These questions asked us to look carefully at what students had to say and challenged our initial 'etic' views. Further reading and rereading of these moments in relation to Dewey's account of experience in the classroom and the technical terms he introduces helped us to spot significance in what was said that is easy to overlook. Making the link between what students said and Dewey's ideas of focused experience and collateral growth helped us 
to draw out implications that deserve consideration in relation to the work of other teachers. This dual approach reduced the risks of subjective bias while giving 'special weight' [24] to our findings and recommendations.

The BERA Ethical Guidelines (2018) ensured that student views were anonymised, students have a sense of the research they participated in and were aware of their right to fully withdraw from the research at any time [25].

\section{Results}

\subsection{Vignette 1: Anita}

Anita came to college with an unclassified grade in maths. Since joining the college she had successfully completed a Level 1 Functional Skills exam and had recently entered the GCSE class.

She had been a part of the established cohort for less than a month when the reported moment of conversation occurred. The class consisted of around 15 learners. The group were engaged in the task of completing a series of the Essential 8 questions in their workbooks. Some students collaborated with others, some worked alone. Anita had been working with a student who didn't attend often and they had been discussing some of the questions.

Teacher: “OK, let's have a look together at how we all got on with those 8 questions. Anita what did you get for question 1?"

Anita: “Why pick on me? You know I've only been in the class a while.

Teacher: Well you have answered every question and been helping others too, so you are as capable as anyone else of answering the questions."

Anita: "But I know it's wrong. I'm always wrong."

Teacher: "Well let's see how wrong" (walks over and peers over student's shoulder). "On this occasion you are wrong, because your answer is correct."

Anita: "But how can it be right? [teacher's name], you don't teach us anything in our lessons"

Teacher: "Errr, Anita, your practice exam score was superb, and you are making great progress"

Anita: “Yeah I know. We learn loads... But you don't teach us. Why do you never teach us?"

Analysis

The encounter draws attention to the fact that there are different definitions of being good at maths at work in this classroom. The fact of a correct answer is seen differently. Anita does not see herself as being the kind of person who can be good at maths. The fact that she gets the answer right appears almost as an annoyance to the student. It challenges her view of who she is. In contrast the maths teacher sees a potentially good maths student in Anita.

The meaning of Anita's remarks about learning without being taught can be read to indicate that Anita's expectations of what maths teaching looks like is not obvious in the practice shaped by the core concept curriculum. The sequenced revisiting of the same set of topics means the student has the chance to consolidate her learning, drawing on her own past positive experience and that of her peers. The teacher's authority as a subject specialist is expressed through his/her creation of a context over time where the confidence to look to oneself is not naïve nor misplaced.

This instance indicates the potential of the core concept curriculum to contribute toward the goal of helping students to realise the power and satisfaction of thinking about things in mathematical ways.

We found Dewey's idea of focused experience helpful in understanding why a curriculum that taught less could be powerful in helping students to learn more. Our everyday experience of getting on with things, our 'mere activity', is 'very gross' [26] (p. 118). This experience is gross because it takes so much for granted. It assumes things will go as they normally do. When we try to learn something 
new or consolidate learning experience needs to become sharpened. Experience zooms in on a small detail in a wider field. This focusing of experience is felt in both an active and passive phase [26] (p. 113). The active phase involves weighing up alternative imagined options and then deciding how to tackle a question and giving it a go. Then comes the passive phase, 'undergoing the consequences' of trying this approach out. It is 'passive' because what comes back to us, what we find out, is beyond our control. We get the answer right or wrong. Anita's learning success through reengaging with the same concepts on repeated occasions illustrates the power of a curriculum that makes room for focused experience.

\subsection{Vignette 2: Josh}

This vignette explores the impact of an intervention that was part of a college-wide continuing professional development initiative on Josh's experience of learning maths. An external advisor proposed and 'encouraged' maths tutors to introduce a new starter activity to every session. This consisted of 30 arithmetical questions to answer in a timed $10 \mathrm{~min}$ period.

After completing one of these $10 \mathrm{~min}$ tests, the teacher asked the students to write on the reverse of the test paper how the exercise made them feel. Josh wrote:

"Thanks for showing me I suck at maths".

The teacher intervened and asked him what he meant. Josh replied:

Josh: "We were just getting good at the Essential 8 and now you go and give me this rubbish. I really thought I was getting somewhere and then you go and make me remember that I can't even do simple stuff like this".

Angry, Josh left the classroom.

When Josh returned, he had calmed down.

Josh: "I'm sorry [teacher's name]. I am just sick of being so bad at maths. I honestly thought I was getting better at it and this was just rubbish. It's just like it was at school. I haven't got better at all".

The teacher pointed out how well his Essential 8 questions were going and how arithmetic isn't maths per-se, but it was clear that damage had been done.

Josh: "Yeah I know that I'm getting better at that stuff but all the sums and that. just can't do it fast like the others. It just like it was at school".

Analysis

In this vignette, we see incompatible definitions of being good at maths in play in the approach of the maths advisor, the teacher and the student. The maths advisor values timed maths performance that can be recorded and progress mapped over time. The teacher sees being good at maths as slow process of confidence building where ranked explicit judgements about performance are a potential threat to success. The student, Josh, like Anita, is not sure about the experience of being good at maths. Some experiences seem to hold out the prospect of growth while others confirm the view that being bad at maths is inevitable.

The intervention of the maths advisor draws attention to the way power is exercised. In a situation shaped by a new public management culture, the experience of the teacher and the student appear to be of secondary importance to the need to evidence effectiveness. The goals of the core concept curriculum can appear unrealistic in such a context. The mantra 'teach less to learn more' seems to be at odds with the desire to continually drive up improvement and efficiency. 
Dewey's ideas were helpful in understanding Josh's anger and the teacher's frustration. We thought these ideas drew attention to ways in which the learning process can, at times, be quite fragile and in need of cosseting.

First, the idea of 'focused experience' implies a limit on what can be investigated and learned at any one time. The case of Josh illustrates how focused experience can be overloaded with a set of competing demands. For the confident maths student a quick maths test to 'warm up the brain' appears reasonable. Josh's response shows the dangers of overgeneralisation.

Second, Dewey observes that 'the process [of experience] is a continual spiral. The inescapable linkage of the present with the past is a principle whose application is not restricted to a study of history' [27] (p. 79). This remark reminds us that each person's experience of maths is real for them. What they see in the maths task will be informed by past experiences of learning. Dewey also talks of the 'leap' at the heart of learning something new [26] (p. 129). How the requirement to make this leap feels to the learner will vary greatly. While such leaps are inherently daunting, past experience can encourage us to see the leap as a small puddle to skip over. Alternatively, we might see it as the Grand Canyon, which not even a rocket car can traverse. Josh's response to the core concept curriculum indicates its potential to reduce the perceived width of the learning gap.

\subsection{Vignette 3: Megan}

Megan was a quiet girl who was set to re-sit her maths exam for the third time in as many years. She would often volunteer to distribute sets of different questions (each one on a sheet of A4 paper). She would carefully vet each one before handing it to one of her peers. They were mostly unknown to each other as they were cross-discipline in their main FE studies so maths was their main meeting point. It became a fun exercise as she could reserve trickier ones for those she thought could do with being a little less confident or give easier ones to those she thought less able.

Megan messaged her teacher just after she had missed out on a grade 4 by just 3 marks in her exams.

“Hi [teacher's name]!

Thank you so much for all your help with my maths! I didn't get the 4 I wanted but I still got a 3 which I am so pleased with, to come up from an 1 to a 3 is such an improvement for me and I couldn't of done it without your help! Thank you so so much!

Megan."

Analysis

Incompatible definitions of being good at maths are seen in Megan's recognition of her own gains and the college and government's definitions of success. From the viewpoint of authority, Megan is a failure. The judgement about quality of the maths curriculum that Megan followed, judged in the same way, appears to be ineffective. The right to say what counts as a good curriculum is warranted by the culture of new public management. In this respect, the core concept curriculum may not appear to be a realistic way to teach maths. However, such a judgement would be haunted by the fact that other maths curricula, more in line with the new public management ethos, are themselves playing a role in achieving the current FE pass rate of $5 \%$.

Megan's positive judgement of her own experience of learning maths through the core concept curriculum asks us to look beyond the final achievement grade. Dewey, again, helped us to understand what could be happening here through the idea of collateral learning. He wrote:

"Collateral learning in the way of formation of enduring attitudes, of likes and dislikes, may be and often is much more important than the spelling lesson or lesson in geography or history that is learned. For these attitudes are fundamentally what count in the future." [27] (p. 47). To slightly rephrase this idea, we think Megan's enthusiasm for her experience can be understood in terms of collateral growth. 
Her experience with her peers helped Megan to see herself differently through her growing confidence in maths. Megan's ability to distribute the questions in a way that looked after and challenged her peers relied upon her ability to understand the maths questions and judge the level of difficulty. The expression of kindness to her peers is only meaningful in the context of learning maths. The idea of collateral growth points to the power of subject teaching to equip students for the wider world of work and life. The success of the maths curriculum is seen in part in its ability to give students such grounded and meaningful opportunities to grow. The chance that the core concept curriculum gives students to revisit topics and consolidate learning makes it more likely that all members of the maths cohort can practice looking after others and helping each other to see better who they could be. This section may be divided by subheadings. It should provide a concise and precise description of the experimental results, their interpretation as well as the experimental conclusions that can be drawn.

\section{Discussion}

We present our recommendations as three qualified questions for teachers to consider. Given our experience of working together we think these questions are best considered in discussion with other teachers. As Dewey suggests, such shared working holds out the possibility of developing a more integrated sense of self $[28,29]$ where integration is felt in the ability to state more clearly why you are doing something and why it matters.

\subsection{What Should the Maths Curriculum Be Like?}

This question is hard to answer because, as Dewey reminds us, the classroom situation can never be fully made explicit [30]. It could appear reasonable to paper over this uncertain situation with more and more detail; more detailed lesson plans, more monitoring, all governed by a master curriculum plan. The cacophonous chorus of authoritative demands for this and that outcome give additional impetus to this inclination toward over description and audit. It also reminds us that different accounts of a good maths curriculum at in play and that maths teachers sometimes need to step back and critically evaluate the assumptions shaping curriculum claims. The sense of vertigo that the obscure dimension of the situation can inspire cannot be met by falling into a never-ending search for more detail. Dewey's view that focused experience, by its nature, concentrated on only a few aspects of a situation is one way to ward off the danger of regress. We avoid swamping our capacity to learn by deciding what matters most and then reflecting carefully upon this aspect of the situation. As it goes for the student, so for the teacher; focusing on the core curriculum elements offers more chance of setting up situations where students can make the learning leap.

One way of getting to grips with this question in practice is demonstrated by the example of the development of the Essential 8 Programme. The team developing this curriculum asked themselves what are the essential core, big concepts students really need to tackle to rebuild their confidence in maths. Dewey's account of focused experience asks other teachers to consider what really matters to them in their subject teaching and how best to develop it.

\subsection{What Should the Maths Classroom Be Like?}

One reason this is a hard question to answer is that learning about a good maths classroom often involves studying the virtuosity of others. As Gert Biesta writes, it can be hard to learn in this way because such virtuosity is "not always obvious or visible-also because virtuosity is something that becomes embodied over time-so there is also need for conversation, for talking to teachers to find out why they did what they did." [31]. For example, learning about a good classroom can involve being encouraged to try something out that jars with how we currently see and do things. The leap of learning can involve a leap of faith. Both the student and teacher wishing to learn face the same challenge. Both are helped by recognition of virtuosity in the one they learn from. Furthermore, the fact that the virtuoso's way of seeing the maths problem or teaching situation is not immediately 
evident mean discussion and dialogue are important, in both contexts, to what is going on. Making the time and space for such conversations is not easy.

The mantra 'leave no student behind' encouraged the Essential 8 teaching team to organise their teaching sessions so that there was time for the students to explore what was going on when someone got the answer right. This view of getting to be good at maths was at odds with other views of being good at maths in play for students, other teachers and managers. The fact that different views about what being good at maths were in play often meant a balance to be struck between meeting expectations of progress, the realities of learning new things together and making the most of summative assessment.

\subsection{Who Are We Who Meet Together in the Maths Classroom?}

This is another difficult question to answer; on the one hand, because we are surrounded by ready-made authoritative accounts of what matters. Teachers are expected to embody professional standards, live up to mission statements and perform in ways that show targets have been achieved. Students are required to sign conduct agreements, complete baseline assessments and submit to constant monitoring. Our 'gross experience' of education finds itself being shaped by these imposed priorities. The claim to the self-evident sense of these ways of seeing things again draws attention away from the facts of what our educational expectations are and how we think we should be as students and/or teachers is quite obscure to us [32]. To re-contextualise Homi Bhabha's remarks, [33] a profound sense of unease about who we are told we are is a good sign that things are not right. Acknowledging different views of what is going on raises questions about how realistic a maths curriculum based on a small set of core concepts is. If certain ways of seeing the maths curriculum are recognized to be authoritative, then a view of curriculum that goes against these assumptions risks being judged harshly.

Furthermore, our past experiences of who we have been with others in other settings stands as a valuable resource ready to help us work out a different way forward together. In the vignette of Megan, we see a young woman distributing maths tasks to her peers in a manner reminiscent of an inclusive playground game. The game only works because the roles suit the different players. It is fun because it challenges without overwhelming. Finding out who people are and what they can contribute is something we all do. The context of learning maths gives this ability a particular flavour. The work of the Essential 8 team indicates that collateral growth has more of a chance when there is time to get to know each other. The differences in the cultural backgrounds of classmates can be assets in the shared singular endeavour of becoming good at maths.

\section{Conclusions}

The ethos behind the simplified designs of Dieter Rams that went on to inspire Apple is that 'good design is as little as possible'-less, but better [34] (p. 10). This same ethos could be said to capture what stood behind the development and implementation of the Essential 8 programme. In the context of working with a core concept curriculum, student voices seemed easier to hear. Thinking carefully about what students had to say helped us to recognize that they valued what Dewey called focused experiences, where they had chance to make sense of a limited number of maths topics over an extended period of time. The surprising finding of the research is that some students also recognized that studying the subject of maths had an impact on how they saw themselves as people and what they could see themselves achieving in life. The reader may wish to consider what space there is in their maths classrooms to listen and respond to what students have to say about themselves and their maths learning. How realistic it is to teach maths in a way that makes space will depend, in part, upon how friendly or hostile to such approaches the wider college/organizational context proves to be.

Author Contributions: Conceptualization, L.N. and J.C.; methodology, L.N.; validation, L.N. and J.B.C.; formal analysis, L.N. and J.B.C.; investigation, L.N. and J.B.C.; resources, L.N. and J.B.C.; data curation, J.B.C.; writing-original draft preparation, L.N.; writing-review and editing, L.N. and J.B.C.; visualization, L.N. 
and J.B.C.; supervision, L.N.; project administration, L.N.; funding acquisition, L.N. All authors have read and agreed to the published version of the manuscript.

Funding: Financial support from Education and Training Foundation and academic support for Sunderland University Centre for Excellence in Teacher Training contributed to the work that inspired us to write this paper.

Acknowledgments: Thanks to the students, maths lecturers and leaders of East Sussex College Group for their support and honest accounts of teaching and learning maths at the Eastbourne campus and Lewes campus.

Conflicts of Interest: J.C. originally devised the Essential 8 maths programme and conducted the field research as an insider researcher. The risk of subjective bias was mitigated by the collaborative development of the issue questions and the shared analysis data in terms that took us well beyond narrow concerns with effectiveness. The funders had no role in the design of the study; in the collection, analyses, or interpretation of data; in the writing of the manuscript, or in the decision to publish the results.

\section{References}

1. Ball, S.J. The Education Debate. Policy and Politics in the Twenty-First Century, 3rd ed.; Policy Press: Bristol, UK, 2017.

2. Higton, J.; Archer, R.; Dalby, D.; Robinson, S.; Birkin, G.; Stutz, A.; Smith, R.; Duckworth, V. Effective Practice in the Delivery and Teaching of English and Mathematics to 16-18 Year Olds; Department of Education: London, UK, 2017.

3. The Most Able Students: An Update on Progress Since June 2013. Available online: https://www.gov. uk/government/publications/the-most-able-students-an-update-on-progress-since-june-2013 (accessed on 10 March 2019).

4. The John Roan School. Stretch and Challenge Policy. Available online: http://thejohnroan.greenwich.sch.uk/ 272/teaching-and-learning-vision (accessed on 15 July 2017).

5. Further Education and Skills Inspection Handbook; Ofsted: London, UK, 2019.

6. Association of Colleges. Funding. Available online: https:/www.aoc.co.uk/funding-and-corporate-services/ funding-and-finance/funding (accessed on 1 November 2019).

7. Department for Education. Study Programmes for 16- to 19-Year-Olds. Government Response to Consultation and Plans for Implementation; Department for Education: London, UK, 2012.

8. Impetus. Life after School: Confronting the Crisis. Available online: https://impetus.org.uk/assets/ publications/Report/2017-03-14_Impetus-PEF-Confronting-Crisis.pdf (accessed on 12 December 2019).

9. Boaler, J. Mathematical Mindsets; Jossey-Bass: San Francisco, CA, USA, 2015.

10. Cooper, J.; Kazimierczyk, L. The Essential 8. Workbook 1; Cooperstutors: Sussex, UK, 2017.

11. Cooper, J.; Kazimierczyk, L. The Essential 8. Workbook 2; Cooperstutors: Sussex, UK, 2017.

12. Tishaused, J. 2007. Available online: https://researched.org.uk/graham-nuthall-educational-research-at-itsbest/ (accessed on 3 July 2019).

13. Young, M.; Lambert, D. Knowledge and the Future School. Curriculum and Social Justice; Bloomsbury: London, UK, 2014.

14. Dewey, J. Democracy and Education; Macmillan: New York, NY, USA, 1916; pp. 191-192.

15. Plowright, D. Using Mixed Methods; Sage: London, UK, 2010.

16. Von Wright, G. Explanation and Understanding; Routledge \& Kegan Paul: London, UK, 1971.

17. Wittgenstein, L. Philosophical Investigations; Blackwell: Oxford, UK, 1967.

18. Stake, R.E. The Art of Case Study Research; Sage: London, UK, 1995.

19. Stake, R.E. Case studies. In Strategies of Qualitative Inquiry; Denzin, N.K., Lincoln, Y.S., Eds.; Sage Publications: Thousand Oaks, CA, USA, 1998; pp. 86-109.

20. Stake, R.E. Qualitative Research. Studying How Things Work; The Guildford Press: New York, NY, USA, 2010.

21. Car, W. Philosophy, Methodology and Action Research. J. Philos. Educ. 2006, 40, 421-435. [CrossRef]

22. Stenhouse, L. An Introduction to Curriculum Research and Development; Heinemann: Portsmouth, NH, USA, 1975; excited acc.

23. Connelly, F.M.; Clandinin, D.J. Teachers as Curriculum Planners. Narratives of Experience; Teachers College Press: New York, NY, USA, 1988.

24. Flyvbjerg, B. Five Misunderstandings about Case-Study Research. In Qualitative Research Practice; Clive, S., Ed.; Sage: London, UK, 2004; pp. 390-404. 
25. British Educational Research Association [BERA]. Ethical Guidelines for Educational Research, 4th ed.; BERA: London, UK, 2018. Available online: https://www.bera.ac.uk/researchers-resources/publications/ethicalguidelines-for-educational-research-2018 (accessed on 5 January 2019).

26. Dewey, J. Democracy and Education. In The Middle Works, 1899-1924; Boydston, J.A., Ed.; Southern Illinois University Press: Carbondale, IL, USA, 1976; Volume 9, pp. 5-129.

27. Dewey, J. Experience and Education; Kappa Delta Pi: New York, NY, USA, 1988; p. 79.

28. Dewey, J. Three Independent Factors in Morals. In The Later Works, 1925-1953; Dewey, J., Boydston, A., Eds.; Southern Illinois University Press: Carbondale, CA, USA, 1981; pp. 279-288.

29. Hildebrand, D. Dewey: A Beginner's Guide; Oxford Oneworld Publications: London, UK, 2008.

30. Hildebrand, D. Experience is not the whole story: The Integral role of Situation in Dewey's Democracy and Education. J. Philos. Educ. 2018, 52, 287-300. [CrossRef]

31. Biesta, G.J.J. The Beautiful Risk of Education; Routledge: London, UK, 2013.

32. Collins, H.M. What is Tacit knowledge. In The Practice Turn in Contemporary Theory; Scatzki, T.R., Cetina, K.K., von Savigny, E., Eds.; Routledge: London, UK, 2001; pp. 107-119.

33. Bhabha, H.K. Cultural diversity and cultural difference. In The Post-Colonial Studies Reader; Ashcroft, B., Griffiths, G., Tiffin, H., Eds.; Routledge: London, UK, 1995; pp. 155-157.

34. Rams, D. Weiniger Aber Besser/Less but Better, 2nd ed.; Die Gestalten Verlag: Berlin, Germany, 2014.

(C) 2020 by the authors. Licensee MDPI, Basel, Switzerland. This article is an open access article distributed under the terms and conditions of the Creative Commons Attribution (CC BY) license (http://creativecommons.org/licenses/by/4.0/). 